\title{
Too many men: the violence problem?
}

\author{
Ryan Schacht ${ }^{1}$, Kristin Liv Rauch ${ }^{1}$, and Monique Borgerhoff Mulder ${ }^{1,2,3}$ \\ ${ }^{1}$ Department of Anthropology, University of California at Davis, Davis, CA 95616, USA
2 Graduate Group in Ecology, University of California at Davis, Davis, CA 95616, USA
${ }^{3}$ Center for Population Biology, University of California at Davis, Davis, CA 95616, USA
}

There is a strong intuitive expectation in both popular lore and conventional evolutionary thinking that more males lead to more violence. Here, we untangle the logic behind this widely held notion with a specific focus on humans. We first review the relation between the intensity of sexual selection in human populations and the adult sex ratio (ASR), and find that it is more in line with recent reformulations of sexual selection theory than with conventional models. We then turn directly to the patterning of violence across human societies in relation to the sex ratio. Although the 'more men, more violence' expectation is not met, it is clear that the patterning of violence is undertheorized and we offer recommendations for steps forward.

\section{More men, more violence?}

A popular explanation for violence (see Glossary) centers on male-biased sex ratios. Paradigmatic is the concern of heightened violence in both India and China in response to growing numbers of extra men (in China termed 'bare branches') that result from son preference and daughterbiased abortion, infanticide, and neglect [1-4]. Given that men are typically more prone to engage in violent competition than are women [5], the inference is that more men will necessarily lead to more violence. This logic is implicit in how many of us understand sexual selection. Essentially, when there are more males than females in a population, males are expected to compete vigorously for the limited number of mating opportunities available [6]. In applying this idea to humans, it is therefore appealing to attribute elevated rates of violent crime to male-biased sex ratios, where there are, essentially, too many men (e.g., $[7,8]$ ).

Although this reasoning is intuitive, we question both its underlying theoretical basis and empirical support, focusing here on violence in human societies. We first highlight recent reformulations within sexual selection theory that challenge our intuitions and generate predictions regarding competition over mates that differ from those derived from conventional sexual selection thinking. We then examine how the opportunity for sexual selection is related to ASR across selected human populations.

Corresponding author: Schacht, R. (rnschacht@ucdavis.edu).

0169-5347/\$ - see front matter

(c) 2014 Elsevier Ltd. All rights reserved. http://dx.doi.org/10.1016/j.tree.2014.02.001
Finally, we review how crime is related to sex ratios, and find no consistent evidence in support of the 'more men, more violence' view. The poor fit between sex ratio and population crime statistics suggests that new lines of evolutionary-ecological investigation, both theoretical and empirical, are needed to better understand the patterning of violence in human societies.

\section{Where does 'more men, more violence' come from?} The 'more men, more violence' expectation derives from multiple sources. The first is simply mathematical. Given that most perpetrators and victims of violence are men, it logically follows that male-biased populations will show higher rates of violent crime compared with similarly sized populations with sex ratios near parity. However, this tells us nothing about male responses to varying sex ratios, it simply assumes additive effects of male violence as men are added to (or women subtracted from) a population.

The second source for this idea lies in the social sciences. During the 1980s, concerned researchers typically linked the escalating rates of violence in communities across Asia to the abnormally high sex ratios of the region [1] and, indeed, murder rates were particularly high in Indian

\section{Glossary}

Adult sex ratio (ASR): the ratio of adult males to adult females in a population. Competition: the process by which two or more individuals attempt to get access to a resource of shared interest; the term is neutral with respect to actual behavior.

Contest competition: an antagonistic interaction between individuals over resources (e.g., mates) where success comes through direct engagement [56]. Evolutionary social science: studies conducted by psychologists, anthropologists, biologists, economists, sociologists, and others that use evolutionary theory to model and/or explain aspects of human behavior typically addressed by their discipline.

Female-biased (i.e., low) sex ratio: more females than males in a population. Male-biased (i.e., high) sex ratio: more males than females in a population.

Mating competition: scramble or contest competition directed at same-sex individuals.

Operational sex ratio (OSR): the ratio of sexually active males to sexually receptive females in a population [6].

Potential reproductive rates (PRR): the hypothetical maximum number of independent offspring produced by males and females per unit time [12].

Scramble competition: a resource attainment strategy where success is determined by differential access [56].

Sex ratio: measures are typically calculated as number of males per 100 females; however, some social scientists and demographers use number of females per 100 males, such that quick reference to cited articles might prove confusing. We use this term here when we are not being specific about the life stage (e.g., birth, adult, operational, or population-wide).

Sexual selection: selection that favors traits that aid in mate acquisition at the expense of same-sex rivals [57].

Violence: the use of physical force to harm individuals or to acquire property, used here to refer to that which might occur between men or intersexually; typically associated with contest competition but can also characterize competition over resources for parental investment (e.g., robbery). 
states and districts with strongly male-biased sex ratios (e.g., [2]). Investigators differ with respect to the implied mechanisms, but typically emphasize male predispositions to violence as motivating this relation (due to elevated testosterone levels; [9]), arguing that the risk of violence is greatest when sex ratios are high because the pool of unmarried men (those most prone to violence) is larger in male-biased rather than female-biased populations [10].

A third source derives from a long-standing model of sexual selection, laid out by Trivers [11], and developed in influential papers by Emlen and Oring [6] and CluttonBrock and Vincent [12], the former with the concept of operational sex ratio (OSR) and the latter with sex differences in potential reproductive rates (PRR). According to the traditional parental investment (PI) model, when one sex is tied up with parental care, or more generally with activities that lower its PRR, the other sex competes over this limited resource, leading to the prediction that the sex in abundance competes more intensely for mating opportunities than does the rarer sex. An ancillary expectation is that this will generate more violence in the more abundant sex. However, this is based on an often unstated assumption that male competition over mating opportunities will entail violence, either through contest interactions with other males, scramble competition over resources, or directly against females. Accordingly, in the evolutionary social science literature, researchers commonly attribute the propensity for violence in men to sexual selection [13-15]. From this perspective, men engage in more violence than do women because female mammals have obligate parental responsibilities and constitute a prize for the most competitively successful males (e.g., [16]).

\section{A closer look at the parental investment model and mate competition}

Plausible though it might seem to link violence to competition over scarce mates, we take a closer look at the current state of thinking about mate competition, starting with the basics.

Building on Bateman's [17] early evidence of greater sexual selection in males than in females, Trivers [11] proposed that the relative PI of the sexes is a key variable controlling the operation of sexual selection. The higherinvesting sex becomes a limiting resource for the sex that invests less, leading to escalated levels of mate competition in the latter. Often, and especially for mammals, females invest more in parental care than do males; therefore, males face higher levels of competition for access to the limited number of females.

Emlen and Oring [6] added the concept of OSR, which is the ratio of sexually active males to sexually receptive females and is highly influenced by patterns of PI. Higher investment by females decreases the amount of time they are 'receptive' to fertilization. Such sex differences in the availability of gametes skew the OSR towards males, leading to the claim that males, due to their overrepresentation in the mating pool, face a greater intensity of sexual selection on the traits that make them competitive for relatively scarce females. The same PI that makes females scarce in the OSR also lowers their PRRs and, accordingly, Clutton-Brock and Vincent [12] (see also [18]) proposed that PRRs of males and females can be used to predict patterns of competition over mates (scramble or contest) between the sexes.

According to this perspective, when males are in abundance, they are expected to compete for mating opportunities. In so far as some males are more successful than others in monopolizing these opportunities as a result of heritable traits [19], this is expected to lead to intensified levels of sexual selection on males. Although this competition is often thought of as violent, it need not be (Figure 1).

\section{New thinking about sexual selection alerting us to the importance of ASRs}

In recent years, several flaws have emerged in the conventional model of parental investment [11], in particular its implications for sexual selection [20,21] (Box 1). Building on this work, Kokko and Jennions [22] provide a more dynamic approach to modeling parental investment by endogenizing into the model the availability of males and females. One consequence of this is to think more carefully about the role of the ASR in affecting competition over mates. As noted above, the traditional PI model, especially in conjunction with Emlen and Oring [6], predicts that an abundance of males will lead to greater mating competition among males, whereas the newer model challenges this. It shows that, all things being equal (a sticky point to which we return), in male-biased populations males, at least those that have offspring, should be more committed to provisioning parental care compared with males in female-biased populations [22]. In so far as mating and parental effort are not entirely compatible, which typically they are not, this suggests that, in populations with a male-biased ASR, we should generally see less male-male mate competition and more monogamy [23]. Indeed, further models focusing specifically on competition show that, contrary to the intuitions drawn from Emlen and Oring [6], a male-biased OSR only accurately predicts intense sexual selection among males under a limited set of circumstances, most specifically where it is possible for one male to monopolize multiple mates (e.g., temporal 'clumping' of females arriving on a lek; [24]) and even then mate monopolization generally becomes more difficult when there are more competitors [25].

There is empirical support in the nonhuman literature for the general prediction that male-biased sex ratios do not enhance mating competition among males, and might reduce reproductive variance. For example, in shorebirds with male-biased ASRs, female-female competition and male paternal care (and even polyandry) prevail, as in the jacanas (Jacanidae) and greater painted-snipe (Rostratula benghalensis), whereas species with polygyny, such as the ruff (Philomachus pugnax), have female-biased ASRs [26]. Similarly in insects, males invest heavily in guarding their mates in response to partner shortages rather than continuing to invest in competitive efforts to acquire additional mates, as in soapberry bugs (Serinethinae) [27]. So what is the evidence for this in humans?

\section{Turning to humans}

As a first step in considering the relation between sex ratio and violence, and following the theoretical advances 

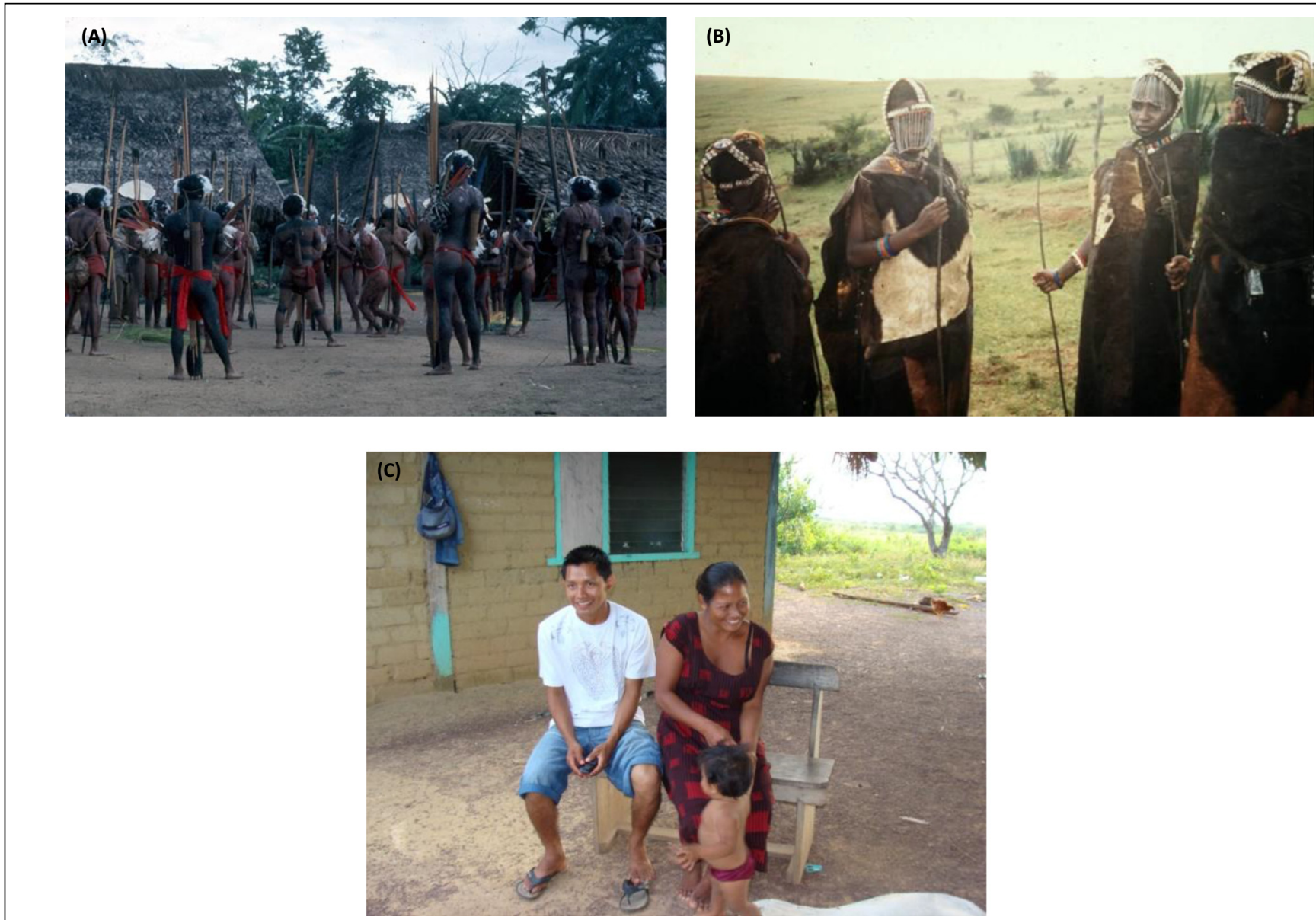

TRENDS in Ecology \& Evolution

Figure 1. Examples of mate acquisition strategies in humans. (A) Among the Yanomamö of Venezuela, men engage in violent contest competition (intervillage raids) to secure mates for polygynous unions; successful warriors have multiple wives [58]. (B) The Kipsigis of Kenya also practice polygyny, but men engage in scramble competition to secure the resources that attract newly initiated young women; men with more resources acquired through trade, theft, and inheritance are those with multiple wives [59]. (C) Among the Makushi of Guyana, monogamous marriage is the most common type of union; because men perform brideservice (grooms work for brides' families to marry) and postmarital residence is matrilocal (a groom lives with his bride's family), success entails securing a single long-term mate [60]. As is evident from these three examples, not all mating competition is violent and not all mate acquisition strategies enhance variance in male reproductive success. Reproduced, with permission, from Ray Hames (A), Philip Arap Bii/Monique Borgerhoff Mulder (B), and Ryan Schacht (C).

outlined above, we need a clearer picture of the relation between sexual selection and ASR. To take an empirical approach to this question in humans, we collated the data of human behavioral ecologists who have collected largely comparable demographic data in primarily predemographic transition, small-scale communities across the world $[28,29]$. Using both published sources and personal communications on these 15 populations, we examine the

\section{Box 1. Changing the direction of the causal arrow between PI and sexual selection}

The traditional PI model [11] has been influential in the development of sexual selection theory, but it is logically flawed. The conventional reasoning goes that, because females produce large, costly eggs, male fitness is constrained by access to mates, producing (in most cases) female-biased care and male-biased competition. Criticisms include: (i) sex differences in PI cannot be taken as a determinant of the intensity of sexual selection because this entails committing the faulty logic of the 'Concorde Fallacy' $[22,61]$. Past investment alone is irrelevant to decisions about future behavior; (ii) As with Maynard Smith's [62] classic model relating parental care evolution to sex differences in mating opportunities, Trivers' verbal model lacks internal consistency, violating the requirement of equal average fitness for females and males and effectively making females exogenous to the model $[63,64]$. Although males do have higher PRRs [12], it is actual and not potential rates that matter in terms of selection [65]. To make the model self-consistent, the additional paternity of deserting males must be accounted for, and comes at a cost to the paternity of other males (i.e., the extra mates of successful males must come from somewhere; [21]); and (iii) in the traditional PI model, a male-biased OSR leads to more intense intrasexual selection and greater competition among males due to a shortage of females [6]. However, male-biased OSRs do not necessarily lead to greater intensity of sexual selection. Klug et al. [25] showed how OSR only accurately predicts sexual selection under a limited set of circumstances, most specifically when mate monopolization is strong. In fact, a wise strategy for a male who might face a long wait in between reproductive events if he were to desert, would instead be to stay with his current partner [22]. Thus, the OSR can equally be thought of as a frequency-dependent mechanism that selects for care in the sex that is in abundance.

In sum, the relative abundance of gametes (i.e., more sperm than eggs) generates the conditions for sexual selection. If selection occurs, then patterns of care and competition are affected [47]. Therefore, sexual selection is not an outcome of patterns of $\mathrm{PI}$ as posed in traditional models, but instead care and competition coevolve with the strength of sexual selection [24]. 


\section{Box 2. The sex ratio and opportunity for sexual selection across 15 populations}

We calculated the opportunity for sexual selection $\left(I_{s}\right)$ of males against the sex ratio for each population, selected from the work of human behavioral ecologists working in nonindustrial societies. The $I_{s}$ is a standardized measure of variance in reproductive success (RS) calculated by dividing the variance in RS by the squared mean of mating success [66-68]. It represents the upper limit of the potential strength of sexual selection in a given population (importantly, not the actual strength of sexual selection on specific traits). The $I_{s}$ is useful for cross-population comparisons because it is standardized by mean fitness and describes the variation in mating success, which can indicate sexual selection within a population. Sex ratio is determined from the ethnographers' data on the number of individuals of mating age in their population, hence it approximates ASR.

Summary measures from 15 human populations show the relation between the sex ratio of the local mating pool and $l_{s}$ is negative (Figure 2, main text), suggesting that traditional assumptions regarding a positive relation between the abundance of males and the intensity of sexual selection are not supported. Rather, as the sex ratio becomes more female biased, the opportunity for sexual selection among males increases (see also [31] for a similar conclusion for human populations based on normative mating system categorizations).

We acknowledge that $I_{s}$, as a measure of the opportunity for sexual selection, has flaws. First, high values of $I_{s}$ will have no significance for selection if variance in mating success is random [19]. Second, there is an inherent systematic positive biasing of $I_{s}$ with high ASR [25]. That said, the pattern reported here, showing a negative relation between the sex ratio of the mating pool and the maximum potential for sexual selection, is all the more remarkable. Furthermore, we note that future studies of how the opportunity for sexual selection is related to sex ratios using individual-level data can correct for the inherent bias of $I_{s}$ with high ASR by using the measure of $I_{\text {diff }}$ suggested by Rios Moura and Peixoto [69].

relation between ASR and the opportunity for sexual selection $\left(I_{s}\right.$; Box 2; Figure 2).

The association between the $I_{s}$ of males and the sex ratio of the mating pool is negative, which suggests that there is more mating competition among men in female-biased than in male-biased populations. Despite being consistent with the reformulations of sexual selection, this result (albeit of primarily illustrative significance, given the small sample and use of population averages) will still undoubtedly be viewed as counter-intuitive, and prompts the question, 'what is going on here?'

One might be tempted to point to polygyny, especially given Ember's demonstration that normative polygynous marriage is most common in female-biased populations $[30,31]$. Our data do not support this possibility; some high $I_{s}$ populations are polygynous (e.g., Kipsigis, where some men have up to 12 wives), whereas others exhibit almost exclusively monogamous marriage (e.g., the Hadza). In fact, there is no apparent patterning of the societies in terms of type or stability of marriage, or indeed of the economy (farming, foraging, or herding), although more systematic comparative analysis with bigger samples using individual level data is warranted [28,29]. Furthermore, it is worth noting that, in nonhumans, higher rates of polygyny do not necessarily mean greater sexual selection on males [32,33].

Demographic and social science literature points to other possible explanations for the finding in Box 2. In a famous book entitled Too Many Women, Guttentag and

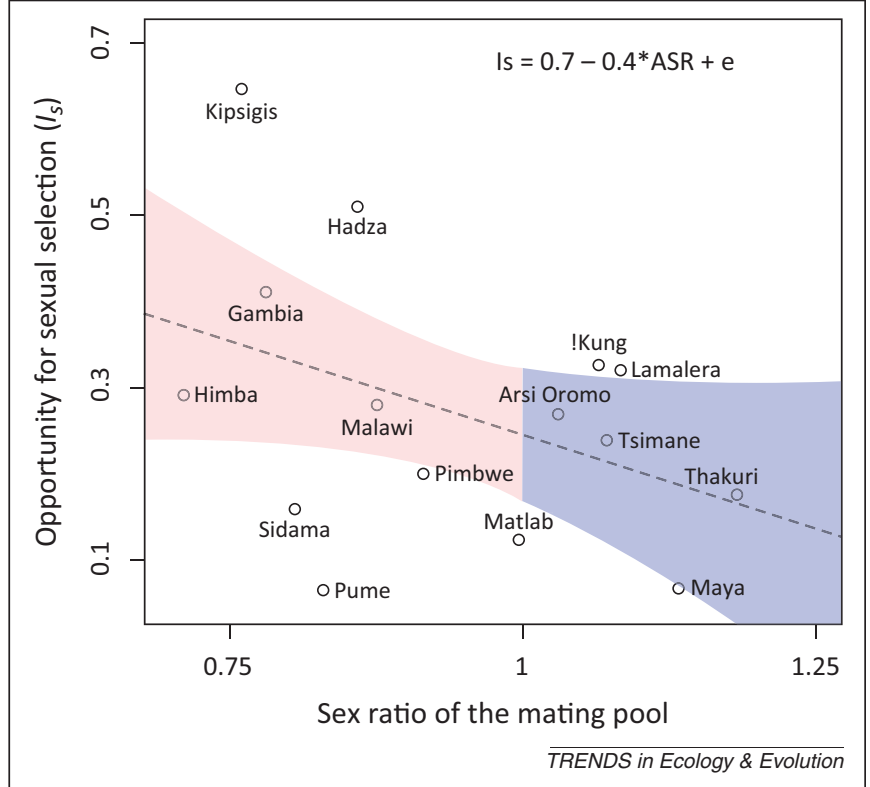

Figure 2. The opportunity for sexual selection and the sex ratio of the local mating pool across 15 populations. The regression line (calculated using maximum likelihood estimation) shows a negative relation between the sex ratio of the mating pool of a population and the $I_{s}$ among males (dashed line) and the $95 \%$ confidence bands (displayed in pink for female-biased sex ratios and blue for malebiased sex ratios). Although the confidence bands are wide enough that a horizontal or upward-sloping regression line could be fitted, the line that best fits the data is negatively sloped. Details on individual data points may be found in $[70-82,97,98]$.

Secord [34] draw from historical accounts and quantitative analyses to demonstrate how sex ratios affect many aspects of the relations between men and women. They show that, in societies with a surplus of women, men find themselves in demand and can leverage their scarcity, behaving promiscuously and offering little parental investment; whereas, when women are in short supply, marriage and a commitment to family are highly valued. A more recent example comes from Colombia, where high male mortality rates, yielding an abundance of women in some regions, are associated with decreased marriage rates and higher proportions of men in concurrent relationships [35]. Cross-cultural research corroborates this pattern, revealing female-biased sex ratios associated with lower levels of male parental investment and higher rates of femaleheaded households [36]. Indeed, when there are too many men, the nature of relationships change. For example, Angrist found that, among immigrants to the USA, high sex ratios had a large positive effect on the likelihood of female marriage and a large negative effect on female labor force participation; with men providing investment, women could avoid wage labor [37]. In general, malebiased sex ratios are associated with a greater proportion of males being married [34,38], less promiscuity in both sexes $[36,39,40]$, and greater conjugal stability [41], all of which might contribute to the lower $I_{s}$ values for men shown in Box 2.

\section{Evidence for more men more violence}

To summarize so far, there are good theoretical and empirical reasons why male mate competition might be more intense where there is an excess of women, not men. How 
Table 1. Sex ratio and violence: a literature review ${ }^{a}$

\begin{tabular}{|c|c|c|c|c|c|}
\hline Sample & Sex ratio measure ${ }^{b}$ & Type of violence $^{c}$ & Violence measure $^{d}$ & $\begin{array}{l}\text { Relation between } \\
\text { violence and } \\
\text { sex ratio }\end{array}$ & Refs \\
\hline 100 countries: UN and World Bank & Complete sex ratio & Homicide & Rate per 100000 & Negative & [55] \\
\hline Countries $(n=70)$ : UN, Interpol, and CIA & $\begin{array}{l}\text { Men and women } \\
\text { (15-64-years old) }\end{array}$ & $\begin{array}{l}\text { Murders, rapes, } \\
\text { and violent assault }\end{array}$ & Rate per 100000 & Negative & [43] \\
\hline India: Government data & Complete sex ratio & Homicide & Rate per 1000000 & Positive & [3] \\
\hline China: Government data & $\begin{array}{l}\text { Men and women } \\
\text { (16-25-years old) }\end{array}$ & $\begin{array}{l}\text { Violent and } \\
\text { property crime }\end{array}$ & Arrests per 10000 & Positive & [84] \\
\hline HRAF and Ethnographic Atlas & Complete sex ratio & Warfare mortality & Low versus high & Negative & [30] \\
\hline Nation sample $(n=45)$ : WHO and UN & Complete sex ratio & Homicide & Rate per 100000 & Negative & [87] \\
\hline US: census and FBI & Five-year groupings & Rape & Arrest per 100000 & Negative & [42] \\
\hline India: crime in India database & Complete sex ratio & Homicide & Rate per 1000000 & Positive & [2] \\
\hline Nations $(n=46)$ : WHO and UN & Complete sex ratio & Homicide & Rate per 100000 & Negative & [88] \\
\hline Nations $(n=46)$ : World Values Survey & $\begin{array}{l}\text { Men and women } \\
\text { (18+-years old) }\end{array}$ & Homicide & Rate per 100000 & Negative & [89] \\
\hline US counties; FBI and census & $\begin{array}{l}\text { Unmarried men } \\
\text { and women } \\
\text { (18-44-years old) }\end{array}$ & Homicide & Rate per 100000 & Unassociated & [90] \\
\hline US cities $(n=217)$ : FBI & Complete sex ratio & $\begin{array}{l}\text { Female homicide } \\
\text { victimization }\end{array}$ & Rate per 100000 & Positive & [45] \\
\hline
\end{tabular}

${ }^{a}$ We performed a literature search for violence and sex ratio in humans on Web of Science (11 November 2013, $\left.n=64\right)$. Some search results were excluded due to redundancies, lack of empirical data (e.g., book reviews), or irrelevance to the question at hand (e.g., studies looking at the sex ratio of criminal offenders without reference to the population sex ratio). Here, we summarize the results of the remaining papers $(n=20)$, highlighting inconsistencies in the relation between the sex ratio and violence as well as critical methodological differences. Abbreviations: CIA, Central Intelligence Agency; FBI, Federal Bureau of Investigation; HRAF, Human Relations Area Files; NIBRS; National Incident Based Reporting System; WHO, World Health Organization; UN, United Nations.

${ }^{b}$ Measures of sex ratio vary widely, and there is no evidence that the scale of the sex ratio measurements (ranging from national level to village level data) is appropriate to capture the relevant mating pool.

${ }^{\mathrm{c}}$ Types of violent crime included in studies range widely: in some cases, all homicides are included, some include only female victims and others include a mix of physical assault and property crime.

${ }^{d}$ Note that 'rate' can refer to a variety of different measures, including: incidence rates (how often a given crime is committed per unit of population, often estimated from report or arrest rates); offender or offense rates (how many people per unit of population commit a given crime); arrest rates (how many people per unit of population are arrested for a given crime); and report rates (how often a given crime is reported to the authorities per unit of population). When 'rate' is used without these descriptors, it usually means 'incidence rate'. Data on homicide are often preferred in these analyses because homicide report rates are considered the most accurate compared with other crimes, such as rape, which likely go under-reported. Rates are commonly averaged across several years to minimize the effect of random fluctuations during shorter time periods.

does this relate to the patterning of violent competition across societies? We turn back now to our original concern: more men leading to more violence. Having dismantled one leg of this argument (a higher intensity of sexual selection in male-biased populations), how does the expectation of more violence in male-biased populations weather a systematic examination of the evidence?

The results are varied (Table 1), with equal numbers of studies finding either higher or lower rates of violence and crime associated with male-biased sex ratios. Why might this be? Although methodological differences have a role (see footnotes to Table 1), what Table 1 reveals is that there is no simple pattern of violence in relation to sex ratio.
Given the variety of forms that mate acquisition strategies can take (Figure 1), it is inaccurate to assume that mating competition will necessarily involve violent behavior. Likewise, the causes of violent behavior can be unrelated to mating competition, as with mental illness, substance abuse, political uprisings, or anger management (such as 'road rage'). Therefore, expectations of straightforward positive or negative associations between 'violence' and sex ratio are overly simplistic. With this in mind, we can venture explanations for some of the variable patterning of violence with sex ratio shown in Table 1. Comparative studies in the USA and cross-nationally found an abundance of males associated with lower rates of rape 
and sexual assault $[42,43]$. However, several USA studies looking to intimate partner violence and female homicide victimization found more violence directed against women by their partners when men were in excess [44-46]. From these results, one might conclude that the findings here are mixed and unpatterned. However, although 'violence' is present in both high and low sex ratio conditions, rates of particular measures vary. Is the prevalence of rape and sexual assault in female-biased sex ratios consistent with modern predictions of elevated mating effort in males when partners are abundant? Are the higher rates of intimate partner violence in male-biased sex ratios evidence of male mate-guarding strategies when mates are rare and, therefore, difficult to replace? The answers lie in identifying how a particular violent act relates to mating competition, which of course is important for understanding the strength and direction of sexual selection at a particular sex ratio.

\section{Additional complicating factors}

Although ASRs are negatively associated with competition among men over reproduction (Box 2), the patterning of violence across human populations is less easily explained. We have shown that an uncritical acceptance of the 'more males, more violence' prediction from traditional theory is unwarranted, but otherwise there is no straightforward pattern of violence in relation to sex ratio in the studies summarized in Table 1.

This varied relation between violent crime and sex ratio is unsurprising. Modern sexual selection theory identifies additional factors influencing male strategies which might complicate predictions about the effect of ASR on either mating competition or violent behavior. Key factors are the degree of intrasexual variation in quality [47], and the shape of the Bateman gradients that capture the marginal returns to agonistic competition [48]; accordingly, simple predictions might not hold and more encompassing theoretical models are needed.

Other factors that should be taken into consideration when addressing the relation between violent crime and sex ratios are outlined in Box 3. First, as we have stressed above, mate competition is not necessarily violent and violence among men is not necessarily mate competition. Additionally, we note that: (i) behavioral polymorphisms in mating strategies most likely lead some individuals into violence and others not, irrespective of the sex ratio; (ii) the nature and extent of female choice can dramatically influence whether the optimal male mating strategy should include violence; (iii) mating and parental effort are not necessarily mutually exclusive; and (iv) even PI can sometimes entail violence (as in some forms of property crime). Clearly, we have a lot more thinking to do when attempting to use sexual selection to understand patterns of violence in humans.

\section{More theory to the rescue}

Although our understanding of how men use violence to compete for women and, more generally, how their optimal reproductive strategies are affected by sex ratio, is greatly undertheorized, current models point to some potential avenues towards a more precise understanding of the
Box 3. Why violent crime and sex ratio show such messy patterning

- Mate competition is not necessarily violent. For example, one man steals, another fights, and a third stays in the office, each gaining resources or status to acquire a mate; similarly, some men might display good genes through violence, others through artistic expression. In these examples, the motivation and outcomes might be the same, but the context can impose different constraints on behavioral options, thereby influencing patterns of violent crime. Social scientists rarely delineate the range of possible responses to female shortages: unmarried men might migrate to regions with more women, patronize prostitutes, resort to polyandrous marriage, or even set up bachelor households and 'bachelor villages', as reported for contemporary China [91].

- Male violence is not necessarily mate competition. Accordingly, crime statistics must be carefully disaggregated to allow precise tests of the ideas presented here. Equating mate competition with violence likely conceals more interesting patterns.

- Behavioral polymorphisms in male mating strategies abound in many species, including humans [92-94]. Models show that, in male-biased ASRs, mated males are selected to provide care [22], but what should unmated males without offspring do? Advertise their caring natures to secure a mate [95], or resort to nastier tactics, such as bar-room brawls (contest competition), property heists (scramble competition), or rape of unguarded females? Decisions here will depend on many factors, such as the man's relative quality, his fighting ability, or the severity of sanctions on criminal behavior if detected, which are all issues that need more attention in new studies.

- Female choice affects the relation between ASR and male violence. For example, if females exert choice on male provisioning qualities (and provisioning does not entail violence), then the lowest levels of violence would be observed at highest ASRs [22]. However, if successful provisioning depends on the control of resources through physical competition, high ASRs might be associated with violence.

- Much of the logic above assumes a tradeoff between parenting effort and mating effort, which is not always the case [96]. In some species, providing parental care can be a key element of the mate competition strategy of a male, as in two-spotted goby (Gobiusculus flavescens) [33]. In many human populations, controlling resources enhances a man's mating success and the survival of his children [50].

- Clearly, expecting a positive association between sex ratio and violence entails multiple assumptions that might not necessarily hold across different human populations.

patterning of violence across human societies. Kokko \& Jennions show, counter intuitively, that a particular behavior might be selected for even when it increases mortality rates due to frequency dependent selection. If violent contests entail a higher risk of mortality (which is quite likely), the competing sex will remain the rare one, favoring even more competition among those who survive (a 'vicious' cycle). Conversely, if caring brings a higher mortality risk, the caring sex will become rare and selection will favor elevated rates of care in the opposite sex (a more 'virtuous' cycle; [49]). The relative mortality costs of caring and competing is critical: this is likely why most birds, for which caring brings higher mortality than fighting, show biparental care, whereas most mammals, for whom fighting (and the development of associated traits) brings higher mortality than caring, show so little paternal care [31]. The upshot is that empiricists committed to explaining the patterning of human violence should be quantifying the relative mortality costs associated with caring and 
mate competition across different human societies, a difficult but perhaps not impossible task. Furthermore, evolutionary social scientists and lay commentators alike should not be shocked to find high levels of violence in the rarer sex.

\section{Concluding remarks}

Humans are a good species in which to investigate how violent competition and other traits are related to sex ratio because there are such variable mating systems, from harem polygyny attained through violence among men against women (e.g., Yanomamö; [13]), through resource defense polygyny attained through economic competition among men who are chosen by women or their kin (e.g., Kipsigis; [50]), to situations where men and women choose each other on the basis of individual qualities (e.g., such as the Makushi and Tsimane; [51,60]). This review has suggested that violence is not structured according to predictions from the traditional parental investment model, or to the more intuitive lay rationale that we presented at the outset. Major reasons are that violence in men cannot be entirely attributed to mate competition, mate competition can take many forms, and female-biased sex ratios can create the conditions for intense mating competition among men.

In short, the belief that violence and crime are exacerbated in human populations by an excess of males is overly simplistic. We show in Table 1 that the patterning of violent crime shows no simple association with sex ratio. We discuss reasons why current understandings of sexual selection are as yet inadequately articulated to deal with several critical intervening considerations that we identified in Box 3 . We also recognize that empiricists have failed to quantify some of the key parameters needed to model the relation between violence and sex ratio, such as the relative costs of care and competition, and the role of violence in attaining mates. Finally, we point to a need for a much richer ethology (and ethnography) of human violence; data are primarily drawn from police reports and national statistics that, for the most part (for a remarkable exception see [14]), combine inter- and intrasexual attacks, crime directed at people and property, and crime emanating from different sectors of the population.

The simple message to take from this review is that the often-related claim that when men are more numerous than women, men create a potential social problem (e.g., [52]), rests on a specific set of assumptions about the nature of male-male competition and the extent to which females can make choices over mating. There are policy applications of this research, with serious practical implications for people's lives. Recommendations that a femalebiased sex ratio will alleviate problems of male violence, although well intentioned, could exacerbate the problem (e.g., attempting to reduce bullying by lowering the sex ratio in a classroom; [53]). Likewise, 'tough on crime' policies that incarcerate increasing numbers of men might be contributing to higher rates of violence, rather than alleviating them, through the resulting sex ratio imbalance in highly policed communities (e.g., [54]). Similarly appeals to abolish polygyny because of the dangerous emergence of a class of unmarried men rely on equally flawed logic [7], especially given the evidence that rates of rape, sexual assault [42,43], and male-male homicide [55] are lower where men are in excess. In short, the 'more men more violence' expectation derives from a simplistic interpretation of Trivers' original paper and a failure to appreciate more recent theoretical developments.

\section{Acknowledgments}

For financial support, we thank the University of California, Davis (UCD) (R.N.S.) and the Wissenschaftskolleg zu Berlin (M.B.M.); for discussions and comments on the manuscript, our colleagues in the Human Behavioral Ecology and Cultural Evolution labs at UCD, as well as Alan Krakauer, Gillian Brown, David Lawson, and anonymous reviewers. Hanna Kokko provided particularly detailed and constructive suggestions. Finally, we are indebted to the generous anthropologists whose populations are included in Figure 2, and whose high-quality fieldwork makes comparative anthropology possible.

\section{References}

1 Hudson, V.M. and den Boer, A. (2004) Bare Branches: The Security Implications of Asia's Surplus Male Population, MIT Press

2 Oldenburg, P. (1992) Sex-ratio, son preference and violence in India: a research note. Econ. Polit. Wkly. 27, 2657-2662

3 Drèze, J. and Khera, R. (2000) Crime, gender, and society in India: insights from homicide data. Popul. Dev. Rev. 26, 335-352

4 Trent, K. and South, S.J. (2012) Mate availability and women's sexual experiences in China. J. Marriage Fam. 74, 201-214

5 Campbell, A. (2005) Aggression. In Handbook of Evolutionary Psychology (Buss, D., ed.), pp. 628-652, Wiley

6 Emlen, S. and Oring, L. (1977) Ecology, sexual selection, and the evolution of mating systems. Science 197, 215-223

7 Henrich, J. et al. (2012) The puzzle of monogamous marriage. Philos. Trans. R. Soc. B: Biol. Sci. 367, 657-669

8 Kanazawa, S. and Still, M.C. (2000) Why men commit crimes (and why they desist). Sociol. Theory 18, 434-447

9 Benton, D. (1983) Do animal studies tell us anything about the relationships between testosterone and human aggression? In The Extrapolation from Animals to Man in Psychology (Davy, G., ed.), pp. 281-298, Wiley

10 Hudson, V.M. and Den Boer, A. (2002) A surplus of men, a deficit of peace: security and sex ratios in Asia's largest states. Int. Secur. 26, $5-38$

11 Trivers, R.L. (1972) Parental investment and sexual selection. In Sexual selection and the Descent of Man, 1871-1971 (Campbell, B., ed.), pp. 136-179, Aldine de Gruyter

12 Clutton-Brock, T.H. and Vincent, A.C.J. (1991) Sexual selection and the potential reproductive rates of males and females. Nature 351, $58-60$

13 Chagnon, N.A. (1979) Mate competition, favoring close kin and village fissioning among the Yanomamö Indians. In Evolutionary Biology and Human Social Behavior: An Anthropological Perspective (Chagnon, N.A. and Irons, W., eds), pp. 86-131, Duxbury Press

14 Daly, M. and Wilson, M. (1988) Homicide, Aldine de Gruyter

15 McDonald, M.M. et al. (2012) Evolution and the psychology of intergroup conflict: the male warrior hypothesis. Philos. Trans. $R$. Soc. B 367, 670-679

16 Wrangham, R. and Peterson, D. (1996) Demonic Males: Apes and the Origins of Human Violence, Houghton Mifflin

17 Bateman, A.J. (1948) Intra-sexual selection in Drosophila. Heredity 2, 349-368

18 Clutton-Brock, T.H. and Parker, G.A. (1992) Potential reproductive rates and the operation of sexual selection. Q. Rev. Biol. 67, 437-456

19 Sutherland, W.J. (1985) Chance can produce a sex difference in variance in mating success and explain Bateman's data. Anim. Behav. 33, 1349-1352

20 McNamara, J.M. et al. (2000) A dynamic game-theoretic model of parental care. J. Theor. Biol. 205, 605-623

21 Houston, A.I. and McNamara, J.M. (2002) A self-consistent approach to paternity and parental effort. Philos. Trans. R. Soc. Lond. Ser. B: Biol. Sci. 357, 351-362 
22 Kokko, H. and Jennions, M.D. (2008) Parental investment, sexual selection and sex ratios. J. Evol. Biol. 21, 919-948

23 Fromhage, L. et al. (2005) Faithful without care: the evolution of monogyny. Evolution 59, 1400-1405

24 Kokko, H. et al. (2012) Unifying cornerstones of sexual selection: operational sex ratio, Bateman gradient and the scope for competitive investment. Ecol. Lett. 15, 1340-1351

25 Klug, H. et al. (2010) The mismeasurement of sexual selection. J. Evol. Biol. 23, 447-462

26 Liker, A. et al. (2013) The evolution of sex roles in birds is related to adult sex ratio. Nat. Commun. 4, 1587

27 Carroll, S.P. and Corneli, P.S. (1995) Divergence in male mating tactics between 2 populations of the soapberry bug: genetic change and the evolution of a plastic reaction norm in a variable social-environment. Behav. Ecol. 6, 46-56

28 Brown, G.R. et al. (2009) Bateman's principles and human sex roles. Trends Ecol. Evol. 24, 297-304

29 Borgerhoff Mulder, M. et al. (2009) Intergenerational Wealth Transmission and the Dynamics of Inequality in Small-Scale Societies. Science 326, 682-688

30 Ember, M. (1974) Warfare, Sex Ratio, and Polygyny. Ethnology 13, 197-206

31 Kokko, H. and Jennions, M.D. (2012) Sex differences in parental care. In The Evolution of Parental Care (Royle, N. et al., eds), pp. 101-116, Oxford University Press

32 Sousa, B.F. and Westneat, D.F. (2013) Variance in mating success does not produce strong sexual selection in a polygynous songbird. Behav Ecol. 24, 1381-1389

33 Wacker, S. et al. (2013) Operational sex ratio but not density affects sexual selection in a fish. Evolution 67, 1937-1949

34 Guttentag, M. and Secord, P. (1983) Too Many Women? Sage

35 Jones, J.H. and Ferguson, B.D. (2006) Excess male death leads to a severe marriage squeeze in Colombia, 1973-2005. Soc. Biol. 54 140-151

36 Schmitt, D.P. (2005) Sociosexuality from Argentina to Zimbabwe: a 48nation study of sex, culture, and strategies of human mating. Behav. Brain Sci. 28, 247-311

37 Angrist, J. (2002) How do sex ratios affect marriage and labor markets? Evidence from America's second generation. Q. J. Econ 117, 997-1038

38 Pedersen, F. (1991) Secular trends in human sex ratios. Hum. Nat. 2 , 271-291

39 Adimora, A.A. et al. (2013) Sex ratio, poverty, and concurrent partnerships among men and women in the United States: a multilevel analysis. Ann. Epidemiol. 23, 716-719

40 Pouget, E.R. et al. (2010) Associations of sex ratios and male incarceration rates with multiple opposite-sex partners: potential social determinants of HIV/STI transmission. Public Health Rep. $125,70-80$

41 Otterbein, K.F. (1965) Caribbean family organization: a comparative analysis. Am. Anthropol. 67, 66-79

42 O'Brien, R.M. (1991) Sex ratios and rape rates: a powercontrol theory. Criminology 29, 99-114

43 Barber, N. (2000) The sex ratio as a predictor of cross-national variation in violent crime. Cross Cult. Res. 34, 264-282

44 Avakame, E.F. (1999) Sex ratios, female labor force participation, and lethal violence against women: extending Guttentag and Secord's thesis. Violence Against Women 5, 1321-1341

45 Titterington, V.B. (2006) A retrospective investigation of gender inequality and female homicide victimization. Sociol. Spectr. 26, 205-236

46 D'Alessio, S.J. and Stolzenberg, L. (2010) The sex ratio and male-onfemale intimate partner violence. J. Crim. Justice 38, 555-561

47 Queller, D.C. (1997) Why do females care more than males? Proc. $R$. Soc. Lond. Ser. B: Biol. Sci. 264, 1555-1557

48 Arnold, S.J. (1994) Bateman's principles and the measurement of sexual selection in plants and animals. Am. Nat. 144, S126-S149

49 Lehtonen, J. and Kokko, H. (2012) Positive feedback and alternative stable states in inbreeding, cooperation, sex roles and other evolutionary processes. Philos. Trans. R. Soc. B 367, 211-221

50 Borgerhoff Mulder, M. (1990) Kipsigis women's preferences for wealthy men: evidence for female choice in mammals? Behav. Ecol. Sociobiol. $27,255-264$
51 Rucas, S.L. et al. (2006) Female intrasexual competition and reputational effects on attractiveness among the Tsimane of Bolivia. Evol. Hum. Behav. 27, 40-52

52 Griskevicius, V. et al. (2012) The financial consequences of too many men: sex ratio effects on saving, borrowing, and spending. J. Pers. Soc. Psychol. 102, 69-80

53 Tybur, J.M. and Griskevicius, V. (2013) Evolutionary psychology: a fresh perspective for understanding and changing problematic behavior. Public Admin. Rev. 73, 12-22

54 Messner, S.F. and Sampson, R.J. (1991) The sex-ratio, family disruption, and rates of violent crime: the paradox of demographicstructure. Soc. Forces 69, 693-713

55 Antonaccio, O. and Tittle, C.R. (2007) A cross-national test of Bonger's theory of criminality and economic conditions. Criminology 45, 925-958

56 Parker, G.A. (1984) Evolutionary stable strategies. In Behavioural Ecology: An Evolutionary Approach (2nd edn) (Krebs, J.R. and Davies, N.B., eds), pp. 30-61, Sinauer

57 Darwin, C. (1871) The Descent of Man, and Selection in Relation to Sex, Murray

58 Chagnon, N.A. (1988) Life histories, blood revenge, and warfare in a tribal population. Science 239, 985-992

59 Borgerhoff Mulder, M. (1988) Kipsigis bridewealth payments. In Human Reproductive Behaviour (Betzig, L. et al., eds), pp. 65-82, Cambridge University Press

60 Schacht, R. (2013) Cassava and the Makushi: a shared history of resiliency and transformation. In Food and Identity in the Caribbean (Garth, H., ed.), pp. 15-29, Berg Publishers

61 Dawkins, R. and Carlisle, T.R. (1976) Parental investment, mate desertion and a fallacy. Nature 262,131-133

62 Maynard Smith, J. (1977) Parental investment: a prospective analysis. Anim. Behav. 25, 1-9

63 Wade, M.J. and Shuster, S.M. (2002) The evolution of parental care in the context of sexual selection: a critical reassessment of parental investment theory. Am. Nat. 160, 285-292

64 Houston, A.I. et al. (2013) The parental investment models of Maynard Smith: a retrospective and prospective view. Anim. Behav. 86, 667-674

65 Webb, J.N. et al. (1999) Multiple patterns of parental care. Anim. Behav. 58, 983-993

66 Wade, M.J. (1979) Sexual selection and variance in reproductive success. Am. Nat. 114, 742-747

67 Arnold, S.J. and Wade, M.J. (1984) On the measurement of natural and sexual selection: theory. Evolution 38, 709-719

68 Jones, A.G. (2009) On the opportunity for sexual selection, the Bateman gradient and the maximum intensity of sexual selection. Evolution 63, 1673-1684

69 Rios Moura, R. and Peixoto, P.E.C. (2013) The effect of operational sex ratio on the opportunity for sexual selection: a meta-analysis. Anim. Behav. 86, 675-683

70 Sear, R. (2006) Height and reproductive success: how a Gambian population compares to the West. Hum. Nat. 17, 405-418

71 Central Statistical Agency (2007) Ethiopian Census, Central Statistical Agency

72 Kramer, K.L. and Greaves, R.D. (2007) Changing patterns of infant mortality and maternal fertility among Pumé foragers and horticulturalists. Am. Anthropol. 109, 713-726

73 Blurton Jones, N.G. et al. (1992) Demography of the Hadza, an increasing and high density population of Savanna foragers. Am. J. Phys. Anthropol. 89, 159-181

74 Sear, R. (2008) Kin and Child Survival in rural Malawi: are matrilineal kin always beneficial in a matrilineal society? Hum. Nat. 19, 277-293

75 Borgerhoff Mulder, M. (2009) Serial monogamy as polygyny or polyandry? Marriage in the Tanzanian Pimbwe. Hum. Nat. 20, $130-150$

76 Shenk, M.K. et al. (2013) Does absence matter? A comparison of three types of father absence in rural Bangladesh. Hum. Nat. 24, $76-110$

77 Gibson, M.A. and Gurmu, E. (2011) Land inheritance establishes sibling competition for marriage and reproduction in rural Ethiopia. Proc. Natl. Acad. Sci. U.S.A. 108, 2200-2204

78 Howell, N. (2010) Life Histories of the Dobe!Kung: Food, Fatness, and Well-Being over the Life-Span. University of California Press 
79 Gurven, M. et al. (2007) Mortality experience of Tsimane Amerindians of Bolivia: regional variation and temporal trends. Am. J. Hum. Biol. 19, 376-398

80 Nolin, D.A. (2012) Food-sharing networks in Lamalera, Indonesia: status, sharing, and signaling. Evol. Hum. Behav. 33, 334-345

81 Kramer, K. (2005) Maya Children: Helpers at the Farm, Harvard University Press

82 Sanders, C.L. and McKay, K.H. (2013) The search for 'strong medicine': pathways to healthcare development in remote Nepal Using GIS. Technol. Innov. 15, 109-124

83 Brooks, R. (2012) 'Asia's missing women' as a problem in applied evolutionary psychology? Evol. Psychol. 10, 910-925

84 Edlund, L. et al. (2007) Sex Ratios and Crime: Evidence from China's One-Child Policy, Institute for the Study of Labor

85 Lester, D. (1999) Implications of the sex ratio for suicide and homicide. Percept. Mot. Skill 89, 222

$86 \mathrm{Lim}, \mathrm{F}$. et al. (2005) Linking societal and psychological factors to homicide rates across nations. J. Cross Cult. Psychol. 36, 515-536

87 Messner, S.F. and Rosenfeld, R. (1997) Political restraint of the market and levels of criminal homicide: a cross-national application of institutional-anomie theory. Soc. Forces 75, 1393-1416

88 Pratt, T.C. and Godsey, T.W. (2003) Social support, inequality, and homicide: a cross-national test of an integrated theoretical model. Criminology 41, 611-643
89 Schaible, L.M. and Hughes, L.A. (2011) Crime, shame, reintegration, and cross-national homicide: a partial test of reintegrative shaming theory. Sociol. Q. 52, 104-131

90 Schwartz, J. (2006) Effects of diverse forms of family structure on female and male homicide. J. Marriage Fam. 68, 1291-1312

91 Greenhalgh, S. (2013) Patriarchal demographics? China's sex ratio reconsidered. Popul. Dev. Rev. 38, 130-149

92 Draper, P. and Harpending, H. (1982) Father absence and reproductive strategy: an evolutionary perspective. J. Anthropol. Res. 38, 255-273

93 Gangestad, S.W. and Simpson, J.A. (2000) The evolution of human mating: trade-offs and strategic pluralism. Behav. Brain Sci. 23, $573-587$

94 Alonzo, S.H. and Heckman, K.L. (2010) The unexpected but understandable dynamics of mating, paternity and paternal care in the ocellated wrasse. Proc. R. Soc. B: Biol. Sci. 277, 115-122

95 Cashdan, E. (1993) Attracting mates: effects of paternal investment on mate attraction strategies. Ethol. Sociobiol. 14, 1-23

96 Stiver, K.A. and Alonzo, S.H. (2009) Parental and mating effort: is there necessarily a trade-off? Ethology 115, 1101-1126

97 Scelza, B.A. (2011) Female mobility and postmarital kin access in a patrilocal society. Hum. Nat. 22, 377-393

98 Borgerhoff Mulder, M. (1988) Reproductive success in three Kipsigis Cohorts. In Reproductive Success (Clutton-Brock, T., ed.), pp. 419-435, University of Chicago Press 